\title{
DC UPS for Critical Loads
}

\author{
Ganesh S, Chiranjit Ghosh T, Kokilasree R, Nandhakumar M, Md Haroon Alim T \\ Dept. of EEE, Saveetha School of Engineering, Saveetha University, Chennai, Tamilnadu, India
}

\section{Article Info}

Article history:

Received Dec 10, 2010

Revised Jan 23, 2015

Accepted Feb 5, 2015

\section{Keyword:}

Computer power supply

SMPS

Switched mode power supplies Uninterruptible power system UPS

\begin{abstract}
The usual way to avoid a computer shutdown during a mains failure is to connect an uninterruptible power supply system (UPS), which can be suitably modified and fitted inside the computer cabinet by the use of proposed methodology known as a dc UPS. Conventional desk top UPS systems store electricity in form of chemical energy in batteries and when ever mains fail the batteries provide DC power which is then converter to ac by inverter and then fed to the computer in order to save critical data. Thus power from mains or from UPS is fed to switched mode power supply unit which converts it to de to supply the computer motherboard and accessories. Leaving the case of the computer powered by mains, during power failure the dc power is unnecessarily converted to ac and then to dc again in SMPS hence high switching losses and heat is produced there by making the entire system very low efficient. In this work it is proposed to directly feed the dc power from the battery to the computer SMPS system by building a UPS arrangement within the computer system. This not only saves space, it is highly efficient compared to the conventional ups system, easy to carry, low cost and reliable since there is no change over operation is required. A complete design of an ac to de power supply with an internal dc UPS is presented in this paper. A prototype has been fully developed and tested as a PC power supply.
\end{abstract}

Copyright (C) 2015 Institute of Advanced Engineering and Science. All rights reserved.

\section{Corresponding Author:}

Ganesh S,

Dept. of EEE,

Saveetha School of Engineering, Saveetha University, Chennai, Tamilnadu, India

\section{INTRODUCTION}

There are many industrial applications in which if mains falls can cause critical damage, not only to the process involved, but also to the equipment. A common case is information loss caused by the sudden shutdown in PCs. Currently, new company edifices usually have an uninterruptible power system (UPS) that feeds the equipment of the whole building. However, in many other cases, each individual user has to connect a personal UPS to the computer in order to avoid an unexpected shutdown. There are many commercial products of this type but generally, all are ac UPSs - their output voltage is an ac voltage (sinusoidal, square, trapezoidal, etc.) that substitutes the mains voltage. However, the problem can be solved in other ways, i.e., by supplying the dc output voltage of the power supply directly from the battery (dc UPS). This approach is also viable, especially if there is only one dc output. Moreover, if the nominal input voltage is similar to the battery voltage, the solution can be very simple because the same converter can be used and only some kind of switch should be implemented in order to feed the converter from the mains or from the battery. On the other hand, a power conversion should be done if the battery voltage is different from the nominal input voltage, and the common way isto use another dc-dc converter to transform the battery voltage into one similar to the nominal input voltage. Of course, the other option is to obtain the output voltage directly from this auxiliary converter. 


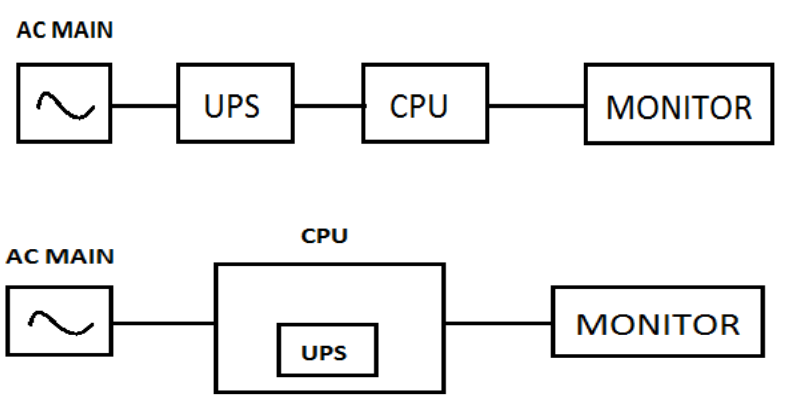

Figure 1. Block diagram of the conventional and proposed system

However, if the power supply has multiple outputs (as in a PC power supply) and all of them are completely regulated, the solution is not so simple because the output voltages cannot be directly obtained from the battery unless the whole power stage is replicated, that is - to have two completely different converters - one operating from the mains and another one operating from thebattery, and both of them obtaining all the output voltages. Apparently, the size and cost of the system will also be duplicated.This paper deals with the design of a power supply with an internal dc UPS that meets all the Advanced Technology extended (ATX) specifications in order to be used as a PC power supply. There are six different output voltages from the ATX, and all of them should be tightly regulated as shown Table 1. It should be noted that the size specifications are also the same, so that this model could fit into the standard chassis of a PC power supply. The goal is not to increase the cost in order to offer a new feature (5-10 min autonomy) at a slightly higher cost than the standard PC power supply cost. This feature could be demonstrated if the PC where placed in the area where experiences frequent mains failures.

Table 1. Voltage Tolerances

\begin{tabular}{cc}
\hline Rail Voltage & Tolerance \\
\hline+5 VDC & $\pm 5 \%$ \\
-5 VDC & $\pm 5 \%$ \\
+12 VDC & $\pm 5 \%$ \\
-12 VDC & $\pm 5 \%$ \\
+3.3 VDC & $\pm 4 \%$ \\
+5 VSB & $\pm 5 \%$ \\
\hline
\end{tabular}

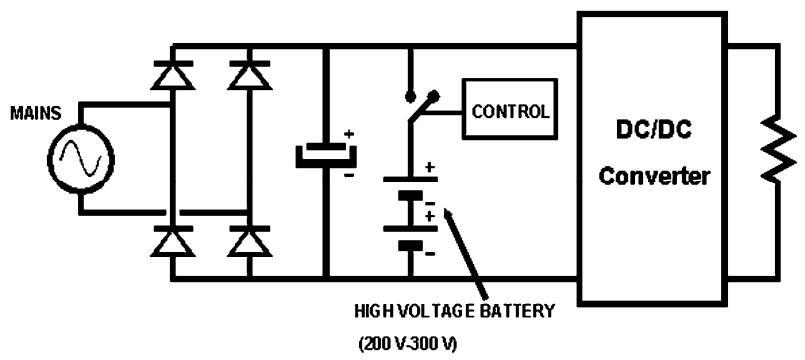

Figure 2. DC UPS based on a high-voltage battery

From the industrial point of view, it could be interesting to design a modular power supply which could be used for other types of applications and not only for a PC, which is a very specific use. Many other industrial equipment need multi-output power supplies but the voltage values can be very different. So, the manufacturer could use the same product for different customers if the output voltages and power ratings can have some adjustment capability.The topology used in this paper is based on the idea of a multi-input converter-one input being the ac mains and the other input being the battery. In previous cases this concept was used with the flyback converter and the forward converter and each individual input had a specific control circuit with a specific pulse-width-modulation (PWM) IC. The topology presented here is based on a half-bridge converter and the battery input is integrated with the secondary winding. Thus, there is no additional specific winding in the transformer to connect the battery. Likewise, there is only one control 
circuit for both inputs and only one PWM IC is used. A simple logic circuit sends the PWM pulses to one input or the other, depending on the voltage of the ac mains. If the mains fail, the logic circuit will send the PWM pulses to the battery input instead of the ac input.

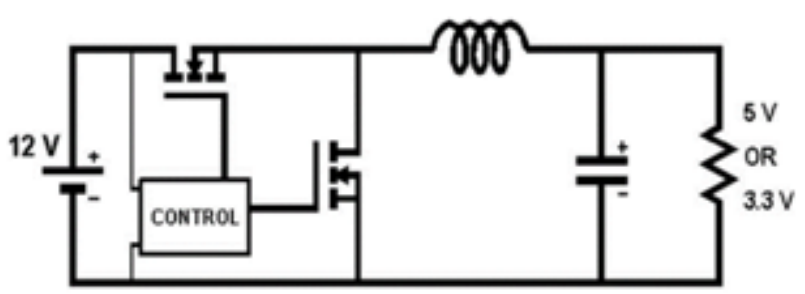

Figure 3. Synchronous buck converter used as a post-regulator

\section{TOPOLOGY SELECTION}

The objective is to design a $200-\mathrm{W}$ power supply outputs that can operate either from the ac mains or from a $12-\mathrm{V}$ battery. It is clear that, from the point of view of the topology, it would be easier to make the power supply operate from a high voltage battery than from a low voltage source. In actual fact, if the battery voltage is high enough (around the peak value of the ac input voltage), we could use the same converter but fed in this case from a dc voltage. The only new element that should be added would be a controlled switch to select the input power source.

However, from the safety (and the reliability) point of view, this option is highly inadvisable. Moreover, high voltage batteries are much more expensive than low voltage batteries. Therefore, the selected voltage is $12 \mathrm{~V}$, mainly due to the extremely low cost of this type of battery. On the other hand, this voltage value complicates the implementation of the UPS considerably because the power supply should operate from two very different input voltages: the mains ac voltage (190-265 V rms) and the $12-\mathrm{V}$ battery dc voltage. The option of using a very wide input voltage range converter has not even been considered because of the performance of these converters. Another important issue in this design is the modularity of the system. Although the objective is to comply with the ATX specifications, particularly as far as size is concerned, it would be very fascinating if we could select the value of the output voltages in order to use the same power supply for different applications. So for this reason, the output of the ac to dc converter is a $12-\mathrm{V}$ output that can drive the total rated power $(200 \mathrm{~W})$. The other outputs are then post regulated from this main one (in our case, the dc to dc converter is a half-bridgeconverter) by means of buck converters. So, any combination of voltage can be obtained by selecting the appropriate post regulators.

Taking into consideration that a PC needs quite low voltages to operate ( 5 and $3.3 \mathrm{~V}$ ), the buck converter designed for this purpose was a synchronous buck converter in order to improve the efficiency as much as possible. Though the use of a synchronous MOSFET is more expensive than the use of a conventional Schottkydiode, the cost of the heat sink needed can be reduced by increasing the efficiency and enlarges the autonomy of the UPS. Moreover, as the input voltage of the buck converter is not too high (12 $\mathrm{V})$, the cost of the control and drive circuit can be further reduced. A special effort made to design a simple, cost effective, and discrete drive circuit avoiding the use of either pulse transformers or expensive commercial drivers. It should be mentioned that the buck output voltage is trimmable from around 9-3 V. Two of these post regulators can be incorporated into the main board and, therefore, the power supply can have up to three different power rails - two of them with a selectable output voltage.

It also have two more outputs $(-12 \mathrm{~V}$ and $-5 \mathrm{~V})$ are also obtained from the main converter. In this case, due to their low power ratings, the $-12 \mathrm{~V}$ output is obtained from the main transformer and regulated by means of cross-regulation methods coupling both output inductors in the same core. The $-5 \mathrm{~V}$ output is obtained from the $-12 \mathrm{~V}$ output by means of a linear regulator connected in cascade. However, the main feature of this power supply is that the UPS should fit into the ATX chassis. As has been mentioned, there are several options to integrate the UPS into the power source. The first option is to put the battery on the primary winding and to use a converter to charge the bulk capacitor directly from the battery. Thus, the main dc to dc converter will always have a similar dc input voltage. With this option, the voltage difference between the input and the output will be quite large (10-14 V to 300-400 V), and it will be necessary to design a specific converter (control system, specific transformer, etc.,) for this purpose. It is important to note that this converter would only operate for a few minutes in case of a mains failure; therefore, its cost should be minimized, although this converter would have to drive the rated power $(200 \mathrm{~W})$. In this case, the best option 
would probably be a flyback converter because of its simplicity, even though the size of the transformer would be large.

(a)

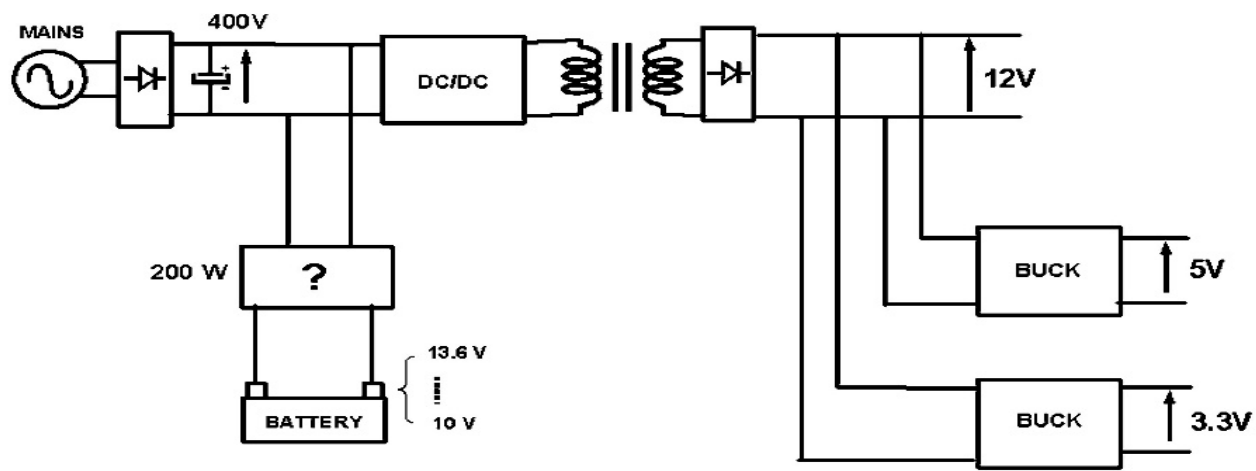

(b)

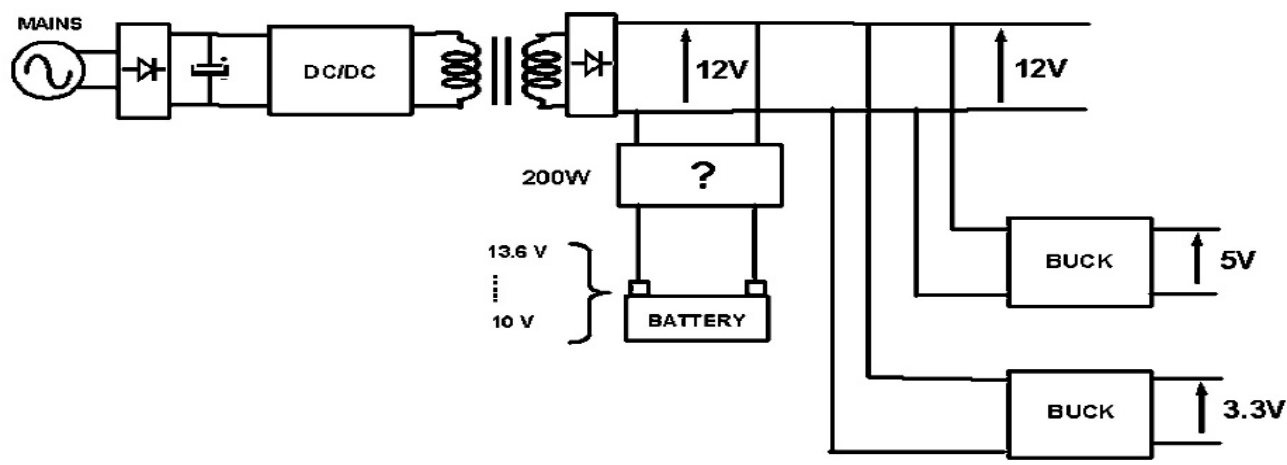

Figure 4. (a) UPS system with battery on primary side (b) DC UPS with battery on secondary side

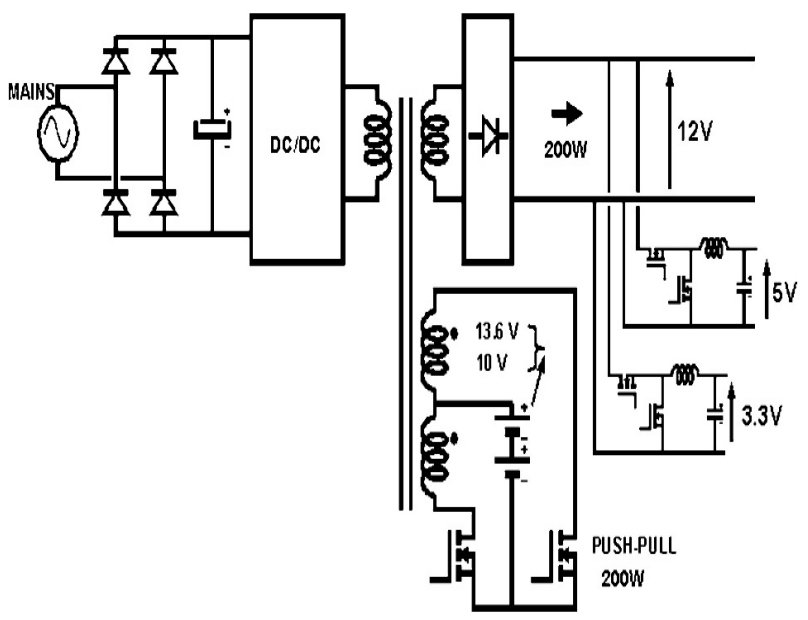

Figure 5. AC/D Converter with a UPS placed on the secondary

Another choice is to put the battery on the secondary winding. At first sight, it seems easier to obtain a closely regulated $12-\mathrm{V}$ output from a similar input voltage. However, this is not obvious at all because the battery voltage can change from around $10.5-13.6 \mathrm{~V}$ and as a consequence, the converter needed should be able to step-up and step-down the output voltage depending on the input voltage. The solution may be to use abuck-boost converter.A better option might be to make proper use of the main transformer and try to drive the power from the battery to the $12-\mathrm{V}$ output by means of an auxiliary winding. We should remember that the main converter is a half bridge; therefore, if the same transformer is used, the winding should be driven in a similar way (a flyback converter could not be connected to this winding because the transformer would be separated). For such case, the best choice seems to be to place the auxiliary winding on the secondary 
winding. As the input and output voltage values are similar, the best solution is to use a push-pull converter because both switches are connected to ground and the transformer is driven symmetrically as in the case of a half-bridge converter. Moreover, the push-pull winding can be integrated in the half- bridge secondary winding.

The main converter input voltage range is $190-265 \mathrm{~V}$ rms. Thus, the input dc voltage ranges from $265 \cdot \sqrt{ } 2=375$ Vdcto $190 \cdot \sqrt{ } 2-20 \%=220 \mathrm{Vdc}(-20 \%$ represents the ripple across the bulk capacitor). If the maximum duty cycle is set around 0.42 in order to have some margin for dynamic regulation purposes at low line conditions, the main transformer turns ratio should be $n=8$. Thus, the maximum duty cycle is 0.43 , the minimum duty cycle is 0.25 , and the nominal duty cycle is around 0.32 . Now, if a mains failure occurs, the push-pull converter will start operating. If this converter is designed to operate with the same duty cycle range as the half-bridge converter, the transition between both modes of operation will be very fast because the regulator will not have to accommodate its voltage levels too much.In a half-bridge converter, the relationship between the inputand the output voltage is

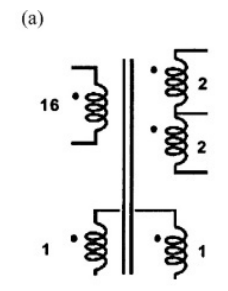

(b) HALF BRIDGE
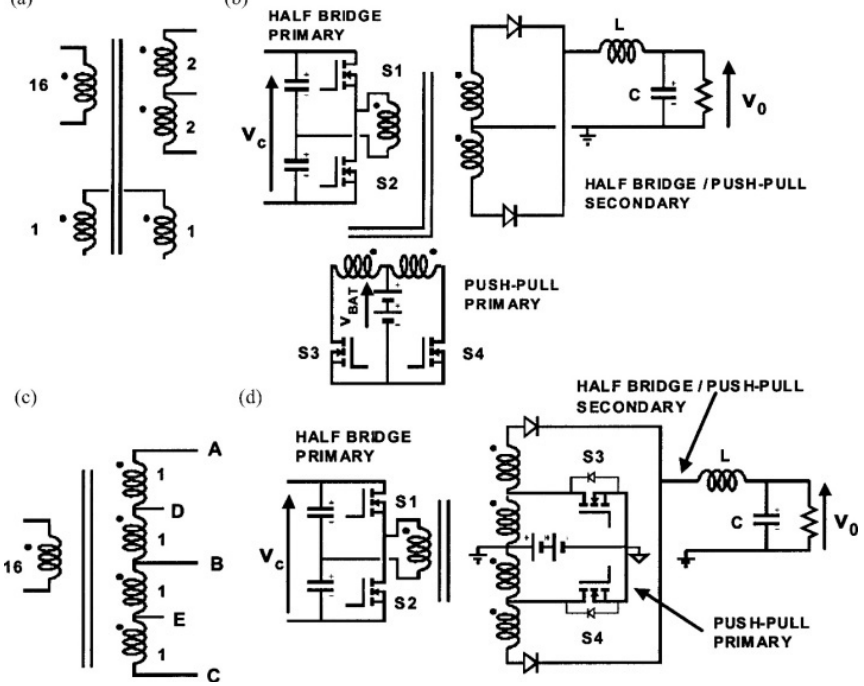

Figure 6. (a) Transformer windings and their number of turns for the basic solution, (b) Half-bridge converter with a push-pull coupled on the same transformer, (c) Rearrangement of the windings to eliminate the specific push-pull windings, (d) Half-bridge converter with a push-pull integrated on the same secondary windings

$$
V 0=\frac{V i n}{\mathrm{n} 1} D
$$

Where Vin1 is the input voltage of the converter and $n 1$ isthe transformer turns ratio between the half-bridge primary winding and the secondary winding. In a push-pull converter, the relationship between the input and the output voltage is

$$
V 0=\frac{2 \cdot \operatorname{Vin} 2}{\mathrm{n} 2}
$$

Where Vin2 is the input voltage of the converter and n2 is the transformer turns ratio between the push-pull primary winding and the secondary winding.If the same output voltage is to be obtained with the same duty cycle, the following expression can be obtained from (1) and (2)

$$
\frac{\operatorname{Vin} 1}{n 1}=\frac{2 . \operatorname{Vin} 2}{n 2}
$$

Let us assume that the average voltage across the bulk capacitor is $300 \mathrm{~V}$ in nominal conditions, the battery voltage is $12 \mathrm{~V}$, and the turns ratio of the half-bridge converter is $n=8$. From (3), the necessary turns 
ratio for the push-pull converter is $\mathrm{n} 2=0.6$ and the closest feasible turns ratio is $\mathrm{n} 2=0.5$. 6Thus, the winding structure of the transformer will be: primary winding 16 turns, each half-bridge secondary winding - two turns, and foreach push-pull primary winding one turn [Figure 6(a)]. Obviously, due to the difference between both input voltage ranges $(375 / 220=1.7$ on the mains and $13.6 / 10=1.36$ on the battery), it is not possible to optimize this feature for the whole range but just for nominal conditions.Furthermore, the small-signal transfer function of both converters is very similar because in both cases, the dynamic behaviour is dominated by the output LC filter. The transfer function of the half-bridge converter is given as

$$
G d 1(S)=\frac{V^{\wedge} 0}{d^{\wedge}}=\frac{\frac{V i n 1}{n 1}}{s^{2} L C+\frac{L}{R} s+1}
$$

And the transfer function of the push-pull converter is given as

$$
G d 1(S)=\frac{V^{\wedge} 0}{d^{\wedge}}=\frac{\frac{V i n 1}{n 1}}{s^{2} L C+\frac{L}{R} s+1}
$$

Where $\mathrm{L}$ is the inductor of output filter, $\mathrm{C}$ is the capacitor of output filter, $\mathrm{v}^{\wedge} 0$ is a small signal perturbation of the output voltage, and $\mathrm{d}^{\wedge}$ is a small signal perturbation of the duty cycle.As the output filter is the same and the turns ratios of both converters have been designed in such a way that the ratio (3) is similar, both transfer functions will be practically identical. Thus, the same voltage regulator can be used if the converter is powered either by the half-bridge or by the push-pull. However, this structure can be rearranged in order to integrate the push-pull windings into the half-bridge secondary windings.

As we know, the voltage waveforms on the trans- former are similar in a half-bridge and in a pushpull. The secondary winding of the half-bridge transformer can then be also used as a push-pull primary winding. Thus, as the battery is placed in the secondary of the power supply and no isolation is needed, the transformer can be used as an autotransformer and share the same winding for the secondary and for the primary of the push-pull converter.Instead of winding each half-bridge secondary altogether ( 2 turns), each turn was wound separately in order to have the middle point available on a pin of the coil former (points D and E), as shown in Figure 6(c).

Thus, in order to implement the push-pull converter, the battery only needs to be connected to the centre point of the whole half-bridge secondary winding (point B) and each MOSFET to the middle point of each leg (points D and E). This way, each push-pull primary has one turn and the secondary has two turns as in the previous arrangement (the diodes of the secondary are connected to points A and B) [Figure 6(c) and (d)]. As we can see, one turn is used both for the primary and the secondary. When the power supply is operating normally using the mains as the input voltage, S1 and S2 are driven as in a conventional halfbridge converter. On the other hand, both S3 and S4 are off. Then, the converter is operating as a conventional half-bridge converter [Figure 7(a)]. The turn ratio between the primary and the secondary is $\mathrm{n} 1$ $=16 / 2$. Thus, the voltage across each one-turn winding is

$$
\mathrm{V} 1 \mathrm{~T}=(\mathrm{VC} /(2.2 . \mathrm{n} 1))
$$

The whole half-bridge secondary will have twice this voltage across it and, hence, (1) can be used just taking into account that the input voltage is the voltage across the bulk capacitor VC.In nominal conditions, the body diodes S3 and S4 do notconduct because the battery voltage is higher than the voltage across the one-turn winding and they are reverse biased

$$
(\mathrm{VC} /(2.2 . n 1))<\text { VBATT }
$$

Only when the input voltage is higher than $245 \mathrm{~V}$ and the battery voltage is near $10 \mathrm{~V}$ can the body diodes become forward biased.In that case, the battery will be in parallel with the secondary windings and a high current can flow through the battery and damage it. To avoid this, a diode has been placed in series with the battery [Figure 7(b)]. If the mains fail, S1 and S2 are turned OFF and S3 and S4 are driven as a conventional push-pull converter and the energy is obtained from the battery. As we can see, the transformer is always driven symmetrically and the secondary will always have a similar voltage waveform [Figure 7(b)]. In this case, the voltage across each one-turn winding will be the battery voltage (VBATT), and hence, the voltage across the whole secondary will be twice this value.Thus, the voltage at the input of theLC filter (VLC) is very similar in both cases (Figure 7(a) and (b)) because, as has been mentioned, n1 and n2 have 
been designedin such a way that the duty cycles are more or less the same.Moreover, in this operation mode, although the primary MOSFETs are off, there is some power flow from the secondary to the primary through the body diodes of S1 and S2. As a consequence, the bulk capacitor will still be charged. The voltage across it will be

$$
\mathrm{VC}=\mathrm{V}_{\text {BATT }} \mathrm{x} 16 \times 2
$$
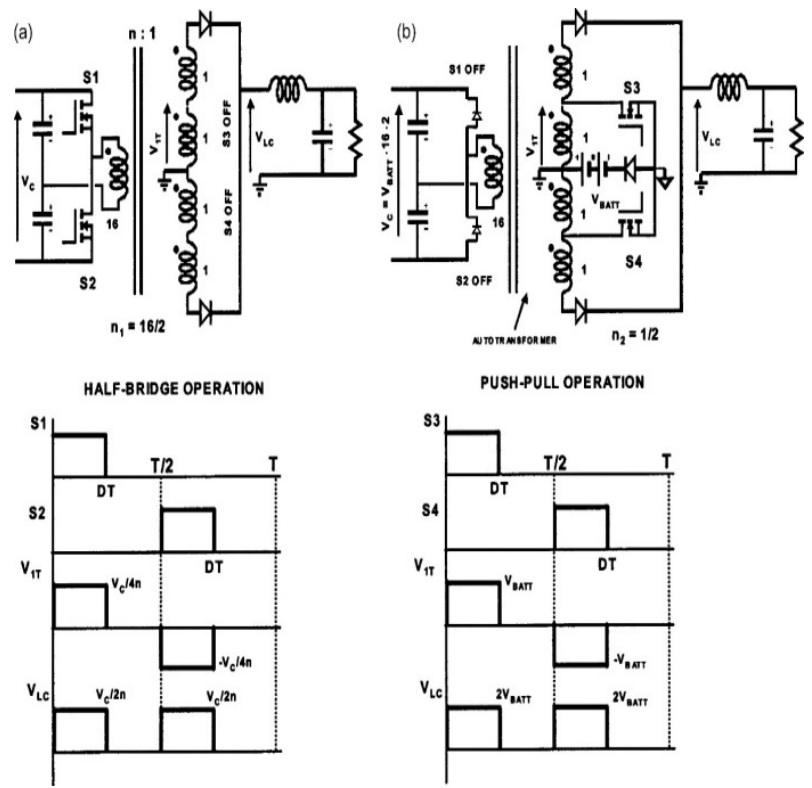

Figure 7. (a) Proposed topology operating as a conventional half-bridge converter and its main waveforms (b) Proposed topology operating as a push-pull converter using an autotransformer

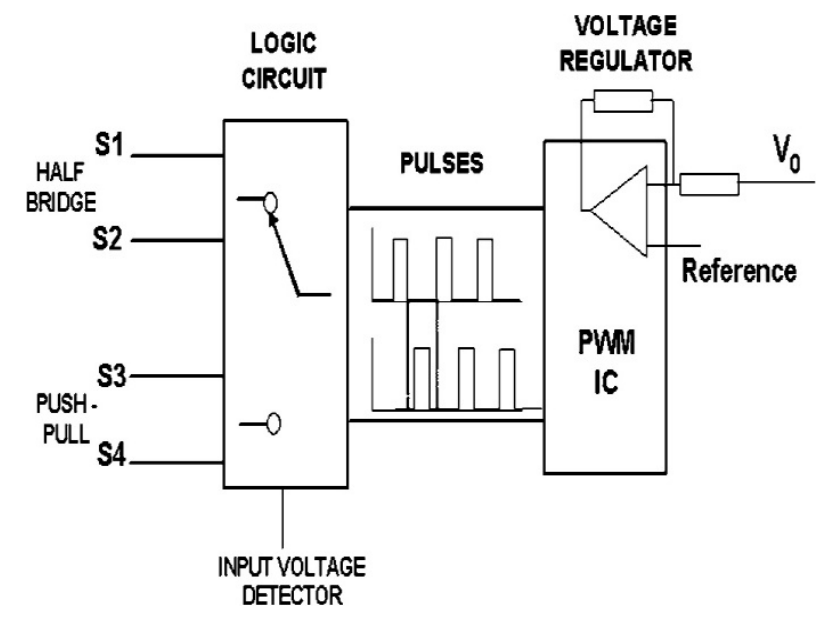

Figure 8. Method used to drive the gate pulses to the half-bridge or to the push-pull

As the battery voltage can change from 10 to $13.6 \mathrm{~V}$, the voltage across the bulk capacitor will change from $320-430 \mathrm{~V}$ when the converter is operating in the UPS mode.A very important feature of this system is that the transition between the normal operation mode and the UPS mode can be done really fast.As mentioned earlier, the small-signal transfer function of both the main half-bridge converter and the push-pull converter are quite similar. Thus, the same PWM controller and the same voltage regulator circuit can be used for both converters to drive the pulses from one converter to the other (Figure 8). Therefore, only one PWM integrated circuit is used and no control or protection circuitry is duplicated. The only extra 
components are the MOSFETs of the push-pull converter no additional windings and no additional circuitry are needed.

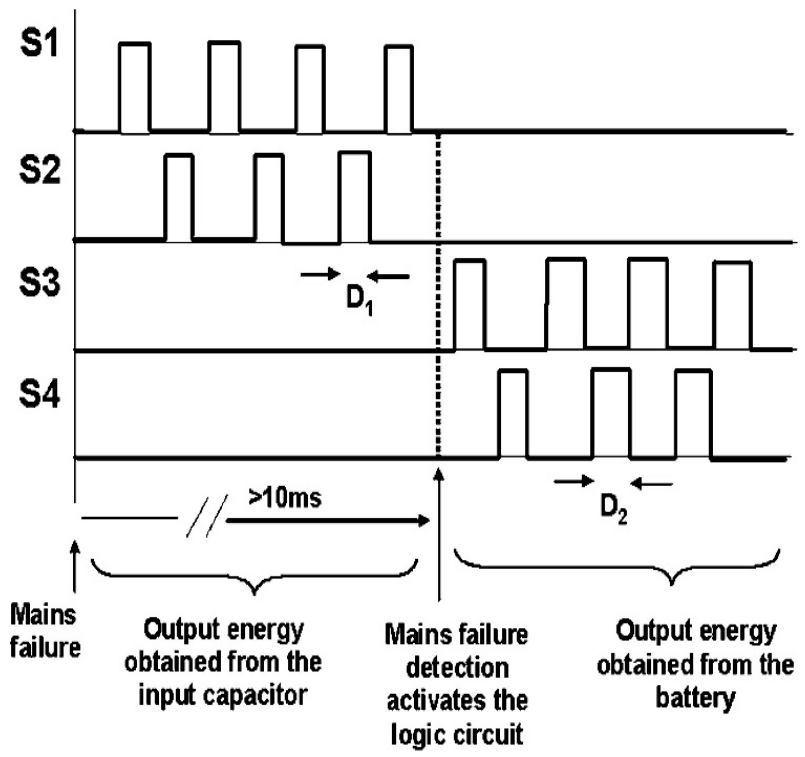

Figure 9. Transition process from the operation using the mains to the operation using the battery

When a mains failure occurs, the input voltage detector circuit activates a logic circuit and diverts the gate pulses from the half-bridge to the push-pull. The transition between both modes of operation can be done in one high frequency switching cycle.As a consequence, the capacitor placed at the $12-\mathrm{V}$ output should not be overdimensioned because it can no longer store any additional energy for the transition time. There will not be any switching cycle with no energy flow from the input to the output. In fact, the ripple during the transition time will be the same as in a conventional switching cycle. The transition will be very fast, even dynamically, due to the design of the transformer's number of turns-as was explained before. During the halfbridge operation, the converter will have a duty cycle (D1). On the other hand, the push-pull will operate with a similar, although not equal, duty cycle (D2) (Figure 9). However, as the difference will be small, the dynamic transition will be very fast and almost no overvoltage will be observed on the $12-\mathrm{V}$ output. Furthermore, as the other outputs are post regulated, no overvoltage will be observed at all.As the input voltage generally ranges from 190 to $265 \mathrm{~V} \mathrm{rms}$, the detection circuit must wait more than $10 \mathrm{~ms}$ to detect a real mains failure. If not, it just could be a small voltage change on the mains but not a real failure. Then, during that time the energy stored on the input bulk capacitor must be able to keep the output voltage perfectly regulated (Figure 9).

However, this capacitor will have a usual value for an ac/dc converter with the conventional hold-up time specifications and it does not need to be over dimensioned. In our case, a $200 \mu \mathrm{F}$ (450 V rated) capacitor was used. With this solution, low voltage MOSFETs can be used for the push-pull, which is much optimized. Therefore, the performance of this converter will be quite good. Note that the current levels will be really high because the full $200-\mathrm{W}$ output power will be obtained from the $12-\mathrm{V}$ battery and then driven by the push-pull. This is important because the better the efficiency of the UPS is, the longer the autonomy will be.Apart from the main power stage, the power supply has another independent ac/dc converter to obtain the +5 VSB voltage. ATX specifications as Table 2 define this output as a stand by voltage that may be used to power circuits that require power input during the powered-down state of the power rails.

Table 2. Voltage and current rating of an ATX power supply.

\begin{tabular}{cc}
\hline $\begin{array}{c}\text { Output } \\
\text { Voltage }\end{array}$ & Current(amps) \\
\hline $12 \mathrm{~V}$ & $6 \mathrm{~A}$ \\
$5 \mathrm{~V}$ & $16 \mathrm{~A}$ \\
$3.3 \mathrm{~V}$ & $14 \mathrm{~A}$ \\
$-12 \mathrm{~V}$ & $0.3 \mathrm{~A}$ \\
$-5 \mathrm{~V}$ & $0.5 \mathrm{~A}$ \\
$+5 \mathrm{VSB}$ & $0.8 \mathrm{~A}$ \\
\hline
\end{tabular}


With our configuration, it is not possible to power one voltage rail and not another; as a consequence, an independent converter is needed. In our case, a very simple fly-back converter was designed using a top switch and, in order to make good use of it, the auxiliary voltage for the control circuitry was also obtained from this converter.

(a)

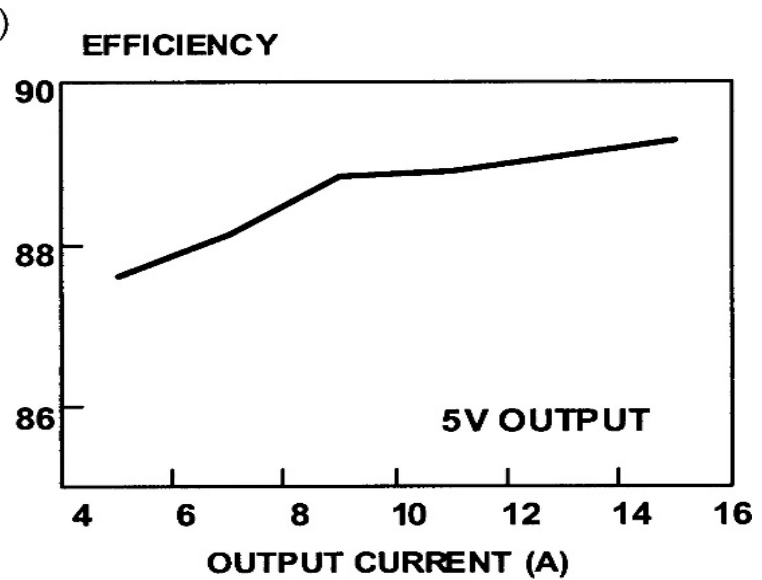

(b) EFFICIENCY

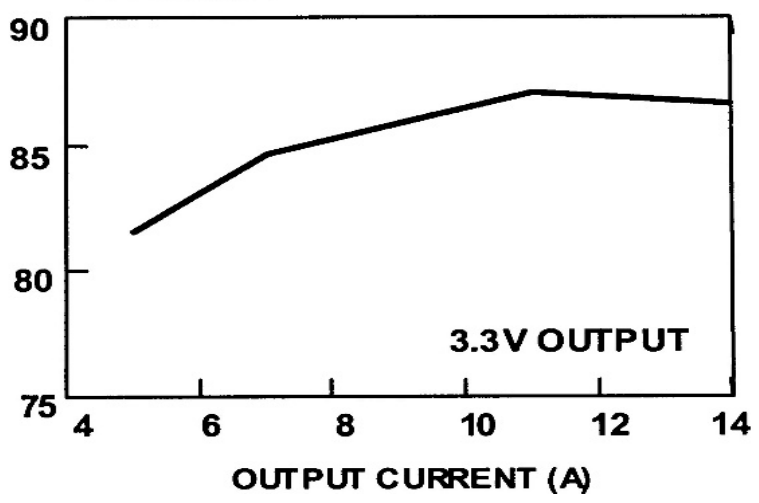

Figure 10. Efficiency of the synchronous buck converter

(a) Output voltage: $5 \mathrm{~V}$, (b) Output voltage: $3.3 \mathrm{~V}$

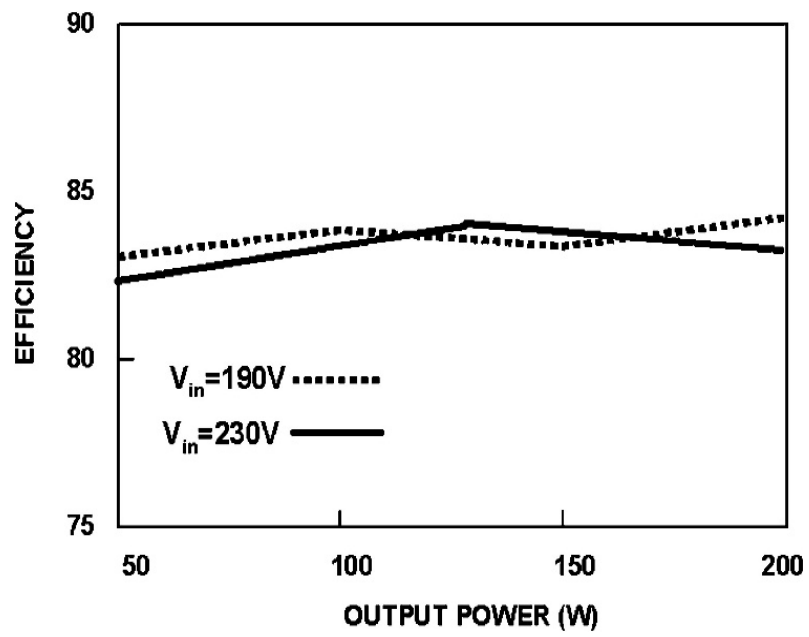

Figure 11. Efficiency of the half-bridge converter and the synchronous buck converters 
When there is a mains failure, the energy is obtained from the battery and hence, this one is discharged. Evidently, a battery charger should be implemented in order to recover the energy used and get the battery ready for the next failure. The battery charger implemented in the prototype is very simple. A nontightly regulated dc voltage is obtained from a winding coupled to the filter inductor. Then, a simple linear current regulator is implemented with a bipolar transistor in or- der to charge the battery at constant current $(220 \mathrm{~mA})$. Finally, when the battery is charged, a hysteretic control strategy is used to keep the battery voltage always between 13.6-13.1 V.

\section{EXPERIMENTAL RESULTS}

A prototype has been fully developed in order to check if the power supplies with the dc UPS (including the 12-V battery) could fit into an ATX chassis. The basic specifications of the power supply are the following:

1) Input voltage: $190-265 \mathrm{~V}$.

2) Different output voltages and the maximum current of each output are shown in Table II.

3) Integrated dc UPS: 7-min autonomy at full power.

4) Maximum Size: $145 \times 142 \times 80 \mathrm{~mm}$.

5) Overcurrent and overvoltage protections on all outputs, PS-ON and PW-OK signals.

6) Compliance with EN60950.

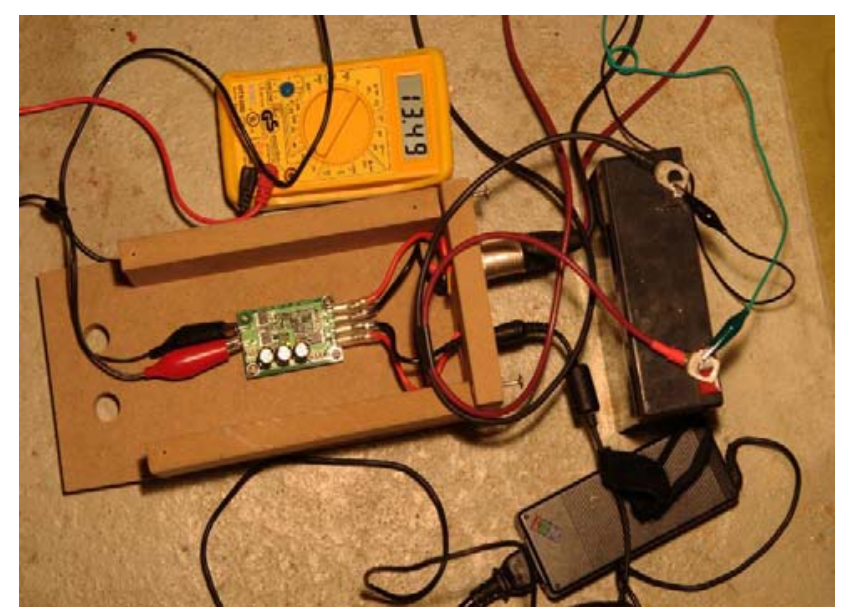

Figure 12. (a) Photograph of the DC UPS system with battery

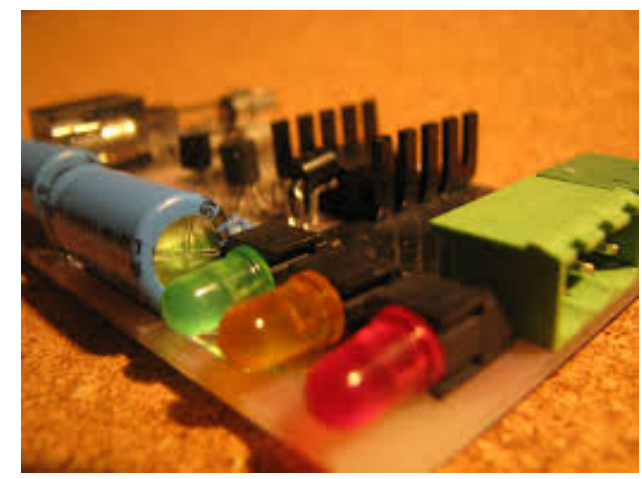

Figure 12. (b) Photograph of the indicators of the DC UPS

In order to give some modularity to the system, the voltage value of both $+5 \mathrm{~V}$ and $+3.3 \mathrm{~V}$ outputs can be adjusted from 3 to $9 \mathrm{~V}(80 \mathrm{~W}$ maximum each). As mentioned earlier, these outputs are obtained from two post regulators based on synchronous buck converters. The total power of both outputs and the $12 \mathrm{~V}$ output is $200 \mathrm{~W}$.

In order to give some modularity to the system, the voltage value of both $+5 \mathrm{~V}$ and $+3.3 \mathrm{~V}$ outputs can be adjusted from 3 to $9 \mathrm{~V}$ ( $80 \mathrm{~W}$ maximum each). As mentioned earlier, these outputs are obtained from 
two post regulators based on synchronous buck converters. The total power of both outputs and the 12-V output is $200 \mathrm{~W}$. The efficiency measured in the prototypes is shown in Figure 10. Figure 10(a) shows the efficiency of the 5-V output and Figure 10(b) shows the efficiency of the 3.3-V output. As we can see, although the control and drive circuit used is very simple, the performance is quite good around $89 \%$ in the $5 \mathrm{~V}$ case, and $87 \%$ in the $3.3-\mathrm{V}$ case. Figure 11 shows the overall efficiency of the prototype when the three main outputs $(12,5$, and $3.3 \mathrm{~V})$ are operating together. Overall efficiency is seen to be around $83 \%$.As far as autonomy is concerned. Table 3 shows the operation in minutes with no ac input. It should be noted that the characteristics of the battery used is: lead acid battery, $12 \mathrm{~V} / 2.2 \mathrm{~A}(138 \times 95 \times 30 \mathrm{~mm})$.

Table 3. Autonomy times of the power supply with a $12 \mathrm{~V} / 2.2 \mathrm{~A}$ battery.

\begin{tabular}{cc}
\hline Output Power & Autonomy \\
\hline $50 \mathrm{~W}$ & $23 \mathrm{~min}$ \\
$200 \mathrm{~W}$ & $7 \mathrm{~min}$ \\
\hline
\end{tabular}

The power supply also implements overvoltage and overcurrent protections on every output, as well as an input voltage detector. The electromagnetic interference (EMI) filter also fitted into the power supply printed circuit board (PCB) and no additional filters should be implemented.Finally, Figure 12 shows the working model of the system with the glowing of LED as a result.

\section{CONCLUSION}

In order to study a different approach to building a UPS for a multiple output power supply, a dc UPS was integrated into an ac/dc converter with all the ATX specifications. For this purpose, a push-pull converter was connected sharing the secondary windings of a half-bridge converter. Both converters drive the transformer in a similar way, and the number of turns of the windings was designed in order to have close duty cycle values on both cases (driving the energy from the half-bridge or from the push-pull). The transition between both operation modes is done through a high frequency switching cycle.

Moreover, in order to give some modularity to the system, two of the outputs were post regulated and their output voltage is selectable from 3 to $9 \mathrm{~V}$. The final size of the power supply fits into a standard ATX chassis. The performance achieved is very interesting, since the power supply we designed can deliver the full 200-W rated power for 7 minutes, which is enough to turn off a computer and save all the work in progress with no damage or information loss. As the size is exactly the same as a standard ATX power supply, building the converter is possible in the industries, and the final cost should not be much higher than the cost of the standard model. Therefore, it could be an interesting product for a customer who needs power supply safety at a low cost.

\section{REFERENCES}

[1] H. Pinheiro and P. Jain. "Comparison of UPS topologies based on high frequency transformers for powering the emerging hybridfiber coaxial networks". in Proc. IEEE Int. Telecommunications Energy Conf. (INTELEC), Copenhagen, Denmark. 1999, pp 11-14.

[2] R. Morrison and M. Egan. "A new single transformer power factor corrected UPS design". in Proc. IEEE Applied Power Electronics Conf. (APEC), Anaheim, CA. 1998, pp. 237-243.

[3] R Arulmozhiyal, K Baskaran. "A rugged converter for use in low battery voltage uninterruptible power systems". in Proc. IEEE Power Electronics Specialists Conf. (PESC), Galway, Ireland. 2000, pp. 1012-1017.

[4] P. Jain and H. Pinheiro. "High frequency triport UPS topologies for emerging fiber networks". in Proc. IEEE Int. Telecommunications EnergyConf. (INTELEC), San Francisco, CA. 1998, pp. 505-512.

[5] M. Jain, M. Daniele, and P. Jain. "High frequency triport topology for low power UPS". in Proc. IEEE Power Electronics Specialists Conf. (PESC), Fukuoka, Japan. 1998, pp. 1796-1802.

[6] H. Matsuo, K. Kobayashi, Y. Sekine, M. Asano, and L. Wenzhog. "Novel solar cell power supply system using the multiple-input DC-DC converter". in Proc. IEEE Int. Telecomm Energy Conf. (INTELEC), San Francisco, CA. 1998, pp. 797-802.

[7] H. Matsuo, T. Shigemizu, F. Kurokawa, and N. Watanabe. "Characteristics of the multiple input DC-DC converter". in Proc. IEEE Power Electronics Specialists Conf. (PESC), Seattle, WA. 1993, pp. 115-120.

[8] K. Ma and Y. Lee. "An integrated flyback converter for DC-uninterruptible power supply". IEEE Trans. Power Electron. vol. 11, no. 2, pp. Mar. 1996. pp 318-327,

[9] E. Rodríguez, D. Abud, and J. Arau. "A novel single-stage single-phase DC UPS with power factor correction". IEEE Trans. Ind. Electron. vol. 46, no. 6, Dec. 1999. pp. 1137-1147.

[10] ATX12V Power Supply Design Guide, Version 2.01, Jun. 2002. 
[11] P. Alou, O. Garcia, J.A. Cobos, J. Uceda, and M. Rascon. "Flyback with active clamp: A suitable topology for low power and very wide input voltage range applications". in Proc. IEEE Applied Power Electronics Conference and Exposition, 2009. APEC2009. pp. 242-248.

[12] J. de la Peña, M. Rivas, A. Huertas, M. Perez, and M. Rascon. "Wide input range module for rectified AC power distribution demonstrator for telecommunications system". in Applied Power Electronics Conference and Exposition, 2002. APEC2002. pp. 1202-1207.

\section{BIOGRAPHIES OF AUTHORS}
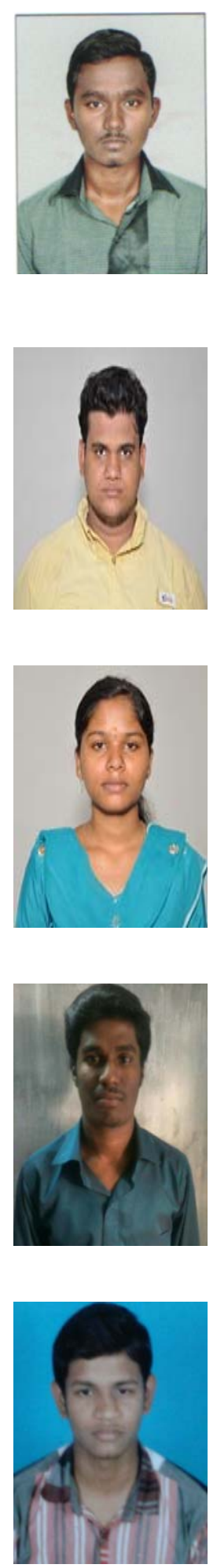

Ganesh was born in 1995. He completed his schooling at Kumaran Asan Higher Secondary School, Chennai. He is now currently studying Bachelor of Engineering course in Electrical Engineering in Saveetha School of Engineering, Saveetha University, Thandalam, Chennai, India. His areas of interest include power electronics converters and application.

Chrinjit was born in 1990. He completed his schooling at Holy Prince Metric Higher Secondary School, Chennai. He is now currently studying Bachelor of Engineering course in Electrical Engineering in Saveetha School of Engineering, Saveetha University, Thandalam, Chennai, India. His areas of interest include power electronics converters and application.

Kokilasree was born in 1994. He completed his schooling at Velankani Metric Higher Secondary School, Krishnagiri. He is now currently studying Bachelor of Engineering course in Electrical Engineering in Saveetha School of Engineering, Saveetha University, Thandalam, Chennai, India. His areas of interest include power electronics converters and application.

Nandakumar Madhavan was born in 1994. He completed his schooling at Paramvir Higher Secondary School, Dharmapuri. He is now currently studying Bachelor of Engineering course in Electrical Engineering in Saveetha School of Engineering, Saveetha University, Thandalam, Chennai, India. His areas of interest include power electronics converters and application.

Mohamed Haroonalim was born in 1995. He completed his schooling at Tagore Metric Higher Secondary School, Salem. He is now currently studying Bachelor of Engineering course in Electrical Engineering in Saveetha School of Engineering, Saveetha University, Thandalam, Chennai, India. His areas of interest include power electronics converters and application. 